\title{
Case Report: Unusual Presentation of Pharyngeal Mucosal Leishmaniasis due to Leishmania (Viannia) braziliensis
}

\author{
Lorena Pinheiro Figueiredo, ${ }^{1,2}$ Laiana do Carmo Almeida, ${ }^{3}$ Andréa Magalhães, ${ }^{1}$ Sérgio Arruda, ${ }^{4}$ Marcus M. Lessa, ${ }^{1,2,3}$ and \\ Edgar M. Carvalho ${ }^{1,4 *}$ \\ ${ }^{1}$ Immunology Department, Professor Edgar Santos University Hospital, Federal University of Bahia, Salvador, Brazil; ${ }^{2}$ Graduate Program in Health \\ Science, Federal University of Bahia, Salvador, Brazil; ${ }^{3}$ Otorhinolaryngology Department, Professor Edgar Santos University Hospital, Federal \\ University of Bahia, Salvador, Brazil; ${ }^{4}$ Gonçalo Moniz Institute, Fiocruz, Salvador, Brazil
}

\begin{abstract}
Mucosal leishmaniasis (ML) affects predominantly the nose and occurs usually weeks or months after the cure of the primary cutaneous lesion. The pathology of $\mathrm{ML}$ is characterized by an exaggerated inflammatory reaction with infiltration of lymphocytes, macrophages, and plasma cells. There is also a paucity of parasites and a strong delayed-type hypersensitivity reaction. Herein, we report a case of a young man who had a large ulcer in his left leg and complained of dysphagia. In nasofibrolaryngoscopy, there were nodular lesions in the oropharynx and rhinopharynx. The skin lesion biopsy showed a chronic inflammation with amastigotes inside macrophages, and DNA of Leishmania braziliensis confirmed the diagnosis of $\mathrm{ML}$ in tissue biopsied from the pharynx. The leishmaniasis skin test was negative. Cytokine evaluation showed lack of production of interferon (IFN)- $\gamma$, interleukin (IL)-1 $\beta$, and IL-17 with enhancement of these cytokine levels after cure.
\end{abstract}

\section{INTRODUCTION}

The tegumentary leishmaniasis (TL) is caused by protozoa of the genus Leishmania and may affect skin and mucosal tissues. In the New World, the disease is mainly caused by Leishmania Viannia braziliensis and more than $90 \%$ of the patients present a well-limited ulcerated lesion, which characterizes cutaneous leishmaniasis (CL). About $3 \%$ of the patients with $\mathrm{CL}$ develop mucosal leishmaniasis (ML), also known as mucocutaneous leishmaniasis, usually weeks or even years after the primary lesion, although less than $20 \%$ of patients with ML have concomitantly cutaneous and mucosal lesions. ${ }^{1}$ More than $95 \%$ of the patients with $\mathrm{ML}$ have disease in the nasal mucosa, specifically in the nasal septum, head of the lower nasal turbinate vestibules, and nasal floor, ${ }^{2}$ and less than $10 \%$ of the patients have disease in the mouth, pharynx, or larynx. ${ }^{3,4}$ Parasite and host factors participate in the pathogenesis of ML. Leishmania braziliensis is polymorphic, and genotypic differences in the chromosomes 24 and 28 are associated with the clinical forms of TL, severity of the disease, and failure to antimony therapy. ${ }^{5,6}$ Mucosal leishmaniasis patients usually have an exaggerated Type- 1 immune response (Th1) type of immune response that leads to tissue damage. ${ }^{7}$ Mucosal leishmaniasis patients have a greater lymphocyte proliferative response to Leishmania antigen and a delayed type hypersensitivity reaction to the Leishmania antigen compared with CL patients. ${ }^{8}$ In vitro analysis of the immune response shows that patients with ML produces more IFN- $\gamma$ and tumor necrosis factor (TNF) than patients with $C L$ and have a decreased ability to down-modulate the immune response by IL-10. ${ }^{7}$ Actually, cells from ML patients have lower expression and lower number of IL-10 receptors than those from patients with CL. ${ }^{9}$ More recently, in both mice and humans, the role of CD8 T cells, inflammasome, and IL-1 $1 \beta$ has been shown to participate in the tissue damage and metastization of $\mathrm{CL} .{ }^{10}$ However, it is not completely clear what are the cells and

\footnotetext{
*Address correspondence to Edgar M. Carvalho, Serviço de Imunologia, Complexo Hospitalar Universitário Professor Edgar Santos, Universidade Federal da Bahia (UFBA), Rua João das Botas $s / n$, Canela, Salvador
} 41110-160, Brazil. E-mail: imuno@ufba.br molecules involved in the tissue damage in TL patients. Here, we report an unusual case of a patient without HIV infection or use of immunosuppressive drugs who developed $\mathrm{ML}$, despite a negative leishmaniasis skin test (LST) and no detectable IFN- $\gamma$ and IL-1 $\beta$ in supernatants of lymphocyte culture.

\section{CASE REPORT}

A male rural worker aged 46 years was referred to the Health Post of Corte de Pedra in January 2018. He was previously healthy when he noticed a skin lesion in his left leg that started 3 months before the medical assistance. He also complained of odynophagia and dysphagia lasting 1 month. He referred inguinal adenopathy but denied fever, nasal obstruction, epistaxis, and rhinorrhea. Physical examination showed a painful ulcerated skin lesion in his left leg, typical of CL, with welllimited edges, erythematous base, and an infiltrated granular fundus, measuring $60 \times 50 \mathrm{~mm}$ (Figure 1). Anterior rhinoscopy was normal (Figure 2A). Papules with a thin fibrin layer were found on the posterior oropharynx wall (Figure 2B). Nasofibrolaryngoscopy showed the presence of multiple papules with fibrinous exudate in the nasopharynx. The lesions in the nasopharynx were similar to the oropharynx ones, but the biopsy was not performed because he was an outpatient. There were no granulomatous lesions in the larynx (Figure 2C). The LST and rapid HIV test were both negatives. Peripheral blood cell count revealed hematocrit $42.3 \%$, hemoglobin 14.5 $\mathrm{g} / \mathrm{dL}$, leukocytes $8,900 / \mathrm{mm}^{3}$, and normal differential leukocyte count.

We carried out biopsy in the leg ulcer and the oropharynx lesion. In the skin sample, we found acanthotic epidermis with fibrinous crust, extensive chronic inflammation in the dermis with focus of necrosis, and amastigotes inside macrophages. In the oropharynx sample, there was a squamous epithelium with an ulcerated area and lymphoplasmacytic inflammatory infiltrate with histiocytes. The PCR was positive for $L$. braziliensis in the skin and mucosa samples. ${ }^{11}$

The patient was treated with intravenous Glucantime (Sanofi/Aventis, Suzano, Brazil) with a dose of $20 \mathrm{mg} / \mathrm{kg} /$ day for 30 days. The oropharyngeal lesion was healed shortly after antimony therapy, and the patient stopped complaining of 


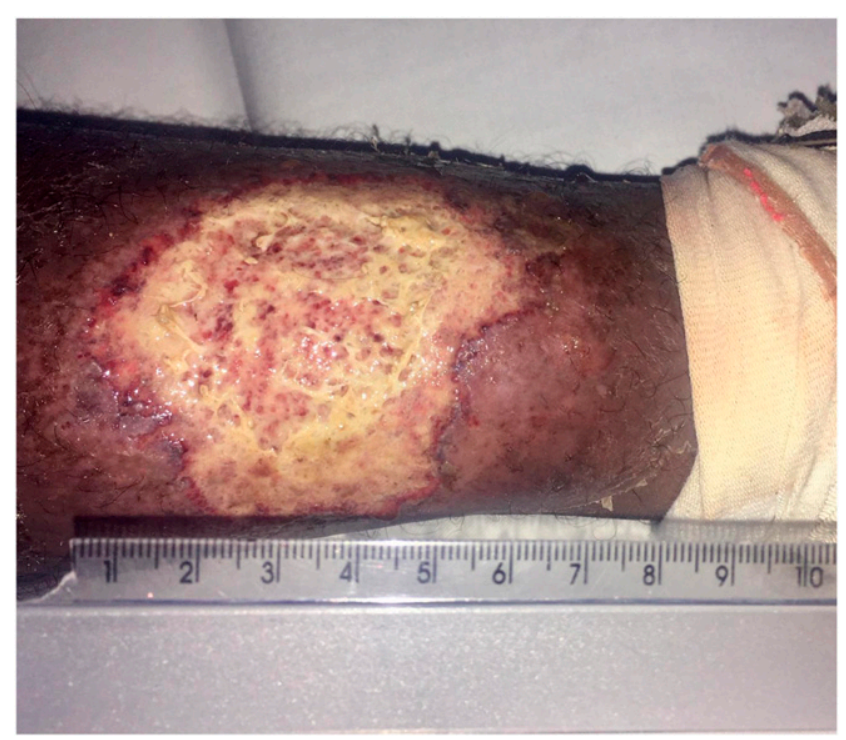

FIGURE 1. Clinical aspect of the left leg ulcer. This figure appears in color at www.ajtmh.org.

dysphagia. However, the cutaneous ulcer remained active, and the patient started therapy with amphotericin B deoxycholate with a total dose of $40 \mathrm{mg} / \mathrm{Kg}$. The complete healing of the ulcer was documented 12 months after the start of therapy. Cytokine production (IFN- $\gamma$, TNF, IL-10, IL-1 $\beta$, IL-17, and granzyme) was measured in supernatants of peripheral blood mononuclear cells stimulated with soluble Leishmania antigen by ELISA. ${ }^{7}$ Before treatment, there was no detectable IFN- $\gamma$, IL-1 $\beta$, and IL-17 levels, but TNF (895 pg/mL), IL-10 (118 pg/ $\mathrm{mL})$, and granzyme $(486 \mathrm{pg} / \mathrm{mL})$ were produced. After treatment, there was an enhancement in IFN- $\gamma(1.519 \mathrm{pg} / \mathrm{mL}), \mathrm{IL}-1 \beta$ (26 pg/mL), IL-17 (47 pg/mL), and granzyme $(2.846 \mathrm{pg} / \mathrm{mL})$ and a decrease in the production of TNF $(8 \mathrm{pg} / \mathrm{mL})$ and IL-10 (28 $\mathrm{pg} / \mathrm{mL}$ ). The LST became positive after clinical cure. He was followed up for 6 months after cure without relapse.

Cytokine production was also performed in four ML patients who had similar age and gender of the case reported. The median and interquartile range of the cytokines were IFN-Y $925 \mathrm{pg} / \mathrm{mL}$ (132-1.613 pg/mL), TNF $247 \mathrm{pg} / \mathrm{mL}$ (47-1.473 pg/ $\mathrm{mL}), \mathrm{IL}-10238 \mathrm{pg} / \mathrm{mL}$ (157-541 pg/mL), IL-1ß $539 \mathrm{pg} / \mathrm{mL}$ (122-894 pg/mL), IL-17 $97 \mathrm{pg} / \mathrm{mL}$ (21-187 pg/mL), and granzyme $3.497 \mathrm{pg} / \mathrm{mL}(1.921-3.921 \mathrm{pg} / \mathrm{mL})$.

\section{DISCUSSION}

Classically, $\mathrm{ML}$ is secondary to the skin lesion. Risk factors for $\mathrm{ML}$ are multiple or extensive skin lesions in $\mathrm{CL}$ patients, disease lasting more than 1 year, and skin lesions above the waist. $^{12}$ The occurrence of concomitant cutaneous and mucosal disease is less common, although an increase from $19 \%$ to $30 \%$ of these cases has been reported in the last two decades. $^{1}$

Usually, ML patients have a strong positive LST and an exacerbated Th1 immune response. ${ }^{7}$ However, more recently, ML has been reported in patients coinfected with HIV and in patients using anti-TNF therapy for systemic rheumatic disease. ${ }^{13-15}$ In such cases, the occurrence of ML is considered as a result of parasite proliferation and dissemination. In patients infected with $L$. braziliensis, the pathogenesis of $M L$ has been associated with an exaggerated inflammatory response mediated mainly by $\mathrm{CD}^{+} \mathrm{T}$ cells, inflammasome activation, and increased production of $\mathrm{IL}-1 \beta .^{16,17}$ It is known that $\mathrm{CD}^{+} \mathrm{T}$ cells in $\mathrm{ML}$ have a predominantly cytotoxic profile. ${ }^{18}$ Although this response has a limited ability to kill parasites, it kills Leishmania-infected cells. ${ }^{17}$ The cell lysis results in the release of damage-associated molecular patterns that activate inflammasome and increase IL-1 $\beta$ production. ${ }^{10} \mathrm{Ac}-$ tually, in mice infected with $L$. braziliensis, neutralization of IL$1 \beta$ prevents the development of mucosal disease. ${ }^{10}$ In the present case, the patient had impairment in producing IFN- $\gamma$, $\mathrm{IL}-1 \beta$ and IL-17, but production of other molecules secreted by $\mathrm{CD}^{+} \mathrm{T}$ cells and macrophages as granzyme and TNF, respectively, was high as observed in the other $\mathrm{ML}$ patients who were used to compare the immune response. We know that TNF participates in the protection and pathology in the Leishmania infection. Whereas anti-TNF therapy is associated with progression of the infection, ${ }^{13-15}$ drugs that decrease TNF production as pentoxifylline when associated to antimony increase the cure rate of $\mathrm{TL}^{19}$ and improve the healing of $M L$ patients refractory to antimony therapy. ${ }^{20}$

Here, we report a case of a patient without comorbidity and without use of immunosuppressive drugs who developed ML in the absence of nasal involvement. He had a negative LST and no detectable levels of IFN-y, IL-17, and IL-1 $\beta$ but produced high levels of granzyme and TNF. This emphasizes the complexity of the pathogenesis of $\mathrm{ML}$, indicating that parasite factors and variety of cytokines and molecules secreted during the parasitic infection may lead to pathology and development of $\mathrm{ML}$, even in the absence of an exacerbated

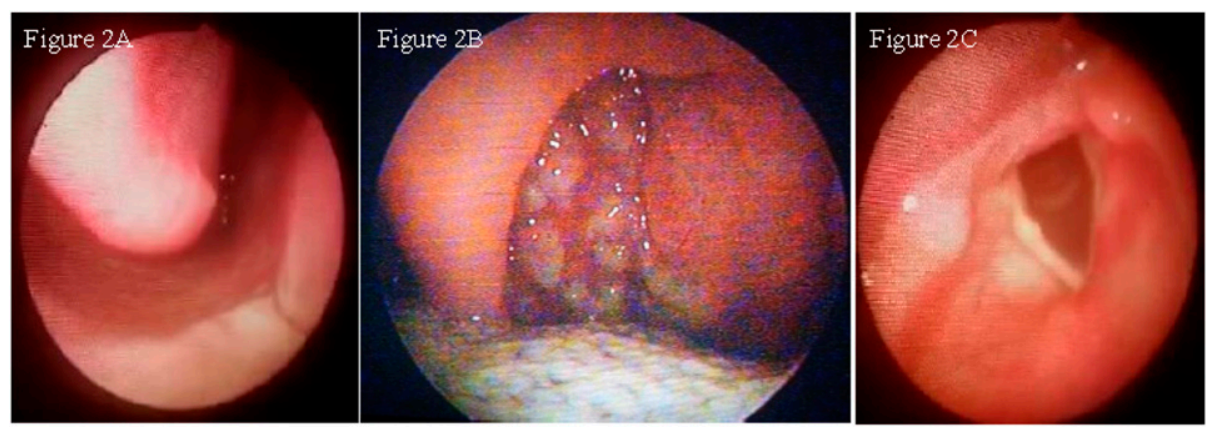

FIGURE 2. (A) Normal anterior rhinoscopy. (B) Posterior oropharynx wall presenting multiple granulomatous lesions. (C) Absence of ulcer and granulomatous lesions in the larynx. This figure appears in color at www.ajtmh.org. 
inflammatory Th1 immune response. The patient authorized the publication.

Received March 27, 2020. Accepted for publication June 14, 2020.

Published online August 3, 2020.

Authors' addresses: Lorena Pinheiro Figueiredo, Federal University of Bahia, Salvador, Brazil, E-mail: Iorenapfigueiredo@gmail.com. Laiana do Carmo Almeida, Andréa Magalhães, and Marcus M. Lessa, Otorhinolaryngologist at Otorhinolaryngology Department, Professor Edgar Santos University Hospital, Federal University of Bahia, Salvador, Brazil, E-mails: laianadoc.almeida@hotmail.com, andrea.imuno@hotmail.com, and marcusmlessa@gmail.com. Sérgio Arruda, Pathologist at Gonçalo Moniz Research Center, Salvador, Brazil, E-mail: arrudasm@gmail.com. Edgar M. Carvalho, Head of the Clinical Research Laboratory in the Gonçalo Moniz Institute, Fiocruz-Ba, Professor of Medicine, Federal University of Bahia, Salvador, Brazil, E-mail: imuno@ufba.br.

\section{REFERENCES}

1. Cincurá C, De Lima CMF, Machado PRL, Oliveira-Filho J, Glesby MJ, Lessa MM, Carvalho EM, 2017. Mucosal leishmaniasis: a retrospective study of 327 cases from an endemic area of Leishmania (Viannia) braziliensis. Am J Trop Med Hyg 97: 761-766.

2. Lessa MM, Lessa HA, Castro TWN, Oliveira A, Scherifer A, Machado P, Carvalho EM, 2007. Mucosal leishmaniasis: epidemiological and clinical aspects. Braz J Otorhinolaryngol 73: 843-847.

3. Marsden PD, 1986. Mucosal leishmaniasis ("Espundia" Escomel, 1911). Trans $R$ Soc Trop Med Hyg 80: 859-876.

4. Boaventura VS, Cafe V, Costa J, Oliveira F, Bafica A, Rosato A, de Freitas LA, Brodskyn C, Barral-Netto M, Barral A, 2006. Concomitant early mucosal and cutaneous leishmaniasis in Brazil. Am J Trop Med Hyg 75: 267-269.

5. Queiroz A, Sousa R, Heine C, Cardoso M, Guimarães LH, Machado PRL, Carvalho EM, Riley LW, Wilson ME, Schriefer A, 2012. Association between an emerging disseminated form of leishmaniasis and Leishmania (Viannia) braziliensis strain polymorphisms. J Clin Microbiol 50: 4028-4034.

6. Silva SC, Guimarães LH, Silva JA, Magalhães V, Medina L, Queiroz A, Machado PRL, Schriefer A, 2018. Molecular epidemiology and in vitro evidence suggest that Leishmania braziliensis strain helps determine antimony response among American tegumentary leishmaniasis patients. Acta Trop 178: 34-39.

7. Bacellar O, Lessa H, Schriefer A, Machado P, Ribeiro de Jesus A, Dutra WO, Gollob KJ, Carvalho EM, 2002. Up-regulation of Th1-type responses in mucosal leishmaniasis patients. Infect Immun 70: 6734-6740.
8. Carvalho EM, Johnson WD, Barreto E, Marsden PD, Costa JL, Reed S, Rocha H, 1985. Cell mediated immunity in American cutaneous and mucosal leishmaniasis. J Immunol 135: $4144-4148$.

9. Faria DR et al., 2005. Decreased in situ expression of interleukin10 receptor is correlated with the exacerbated inflammatory and cytotoxic responses observed in mucosal leishmaniasis. Infect Immun 73: 7853-7859.

10. Novais FO, Carvalho AM, Clark ML, Carvalho LP, Beiting DP, Brodsky IE, Carvalho EM, Scott P, 2017. CD8+ T cell cytotoxicity mediates pathology in the skin by inflammasome activation and IL-1 $\beta$ production. PLoS Pathog 13: e1006196.

11. Weirather JL et al., 2011. Serial quantitative PCR assay for detection, species discrimination, and quantification of Leishmania spp. in human samples. J Clin Microbiol 49: 3892-3904.

12. Llanos-Cuentas EA, Marsden PD, Cuba CC, Barreto AC, Campos $\mathrm{M}, 1984$. Possible risk factors in development of mucosal lesions in leishmaniasis. Lancet 2: 295.

13. Català A, Roé E, Dalmau J, Pomar V, Muñoz C, Yelamos O, Puig L, 2015. Anti-tumour necrosis factor-induced visceral and cutaneous leishmaniasis: case report and review of the literature. Dermatology 230: 204-207.

14. Souza RM, Andrade HF Jr., Duarte MIS, Braz LMA, Schubach AO, Silva FC, Amato VS, 2017. Reactivation of cutaneous and mucocutaneous tegumentary leishmaniasis in rheumatoid arthritis patients: an emerging problem? Rev Inst Med Trop Sao Paulo 59: e6.

15. García-Gonzalez E, Guidelli GM, Bardelli M, Maggio R, 2012. Mucocutaneous leishmaniasis in a patient treated with antiTNF therapy. Rheumatology 51: 1517-1518.

16. Novais FO et al., 2013. Cytotoxic T cells mediate pathology and metastasis in cutaneous leishmaniasis. PLoS Pathog 9: e1003504.

17. Cardoso TM, Machado A, Costa DL, Carvalho LP, Queiroz A, Machado P, Scott P, Carvalho EM, Bacellar O, 2015. Protective and pathological functions of CD8+ T cells in Leishmania braziliensis infection. Infect Immun 83: 898-906.

18. Brodskyn Cl, Barral A, Boaventura V, Carvalho E, Barral-Netto M, 1997. Parasite-driven in vitro human lymphocyte cytotoxicity against autologous infected macrophages from mucosal leishmaniasis. J Immunol 159: 4467-4473.

19. Machado PR, Lessa H, Lessa M, Guimarães LH, Bang H, Ho JL, Carvalho EM, 2007. Oral pentoxifylline and pentavalent antimony for treatment of leishmaniasis: promising but inconclusive evidence of superiority, compared with antimony monotherapy. Clin Infect Dis 44: 788-793.

20. Lessa HA, Machado P, Lima F, Cruz AA, Bacellar O, Guerreiro J, Carvalho EM, 2001. Successful treatment of refractory mucosal leishmaniasis with pentoxifylline plus antimony. Am J Trop Med Hyg 65: 87-89. 